\title{
Impact on traffic and transmission performance of all-optical wavelength converters placed at the network interface or in OXCNs
}

Mikkelsen, Benny; Poulsen, Henrik Nørskov; Danielsen, Søren Lykke; Jørgensen, Carsten; Vaa, Michael; Kloch, Allan; Hansen, Peter Bukhave; Stubkjær, Kristian; Wunstel, K.; Dach, K.

Total number of authors:

14

Published in:

Optical Fiber Communication. OFC 97., Conference on

Link to article, DOI:

10.1109/OFC.1997.719750

Publication date:

1997

Document Version

Publisher's PDF, also known as Version of record

Link back to DTU Orbit

Citation $(A P A)$ :

Mikkelsen, B., Poulsen, H. N., Danielsen, S. L., Jørgensen, C., Vaa, M., Kloch, A., Hansen, P. B., Stubkjær, K., Wunstel, K., Dach, K., Lach, E., Laube, G., Idler, W., \& Schilling, M. (1997). Impact on traffic and transmission performance of all-optical wavelength converters placed at the network interface or in OXCNs. In Optical Fiber Communication. OFC 97., Conference on (pp. 124-125). IEEE. https://doi.org/10.1109/OFC.1997.719750

\section{General rights}

Copyright and moral rights for the publications made accessible in the public portal are retained by the authors and/or other copyright owners and it is a condition of accessing publications that users recognise and abide by the legal requirements associated with these rights.

- Users may download and print one copy of any publication from the public portal for the purpose of private study or research.

- You may not further distribute the material or use it for any profit-making activity or commercial gain

- You may freely distribute the URL identifying the publication in the public portal 


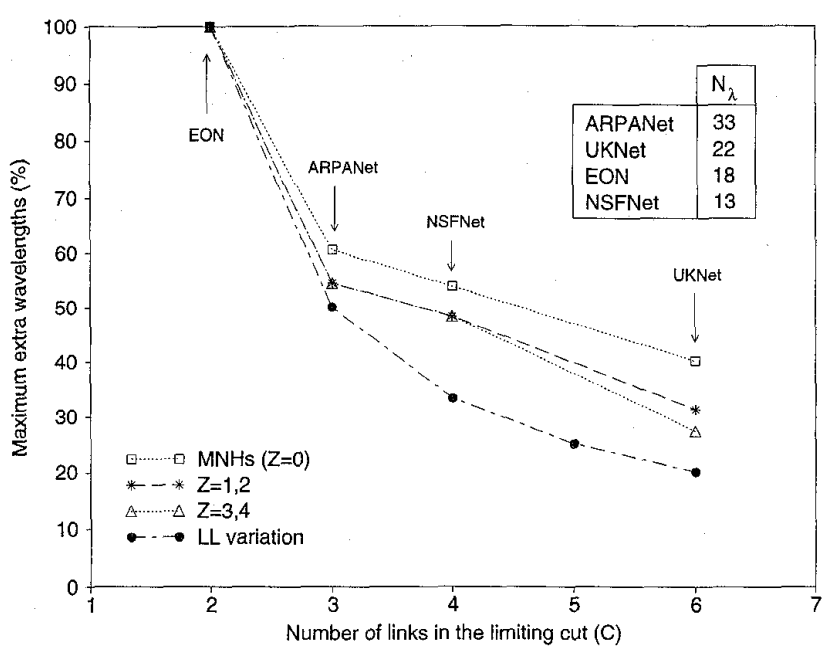

WD5 Fig. 1. Maximum extra wavelengths vs. number of links in the limiting cut $C$.

further increases of $Z$ did not lead to further reduction in the wavelength requirement [the small difference between the results and the LL curve is a consequence of the imposed condition (1)]. A clear trade-off between the maximum increment of the wavelength requirement and $C$ can be seen, indicating that the design of fault-tolerant networks must maximize the number of links in the network limiting cut(s).

Figure 2 shows the average increment in the wavelength requirement versus $Z$. With respect to $M N H$ paths, a reduction was achieved with $Z=1$ and further increase of $Z$ did not lead to any improvement. Hence restoration lightpaths slightly longer than the MNHs ones can be used to reduce the wavelength requirement. On average no more than $20-30 \%$ extra wavelengths are necessary to fully restore the logical connectivity, with the actual value dependent on the initial network link loading. Figure 2 also shows that the increment in the average internodal distance for $Z \geq 1$ was always negligible.

The benefit of wavelength conversion in case of link failure restoration is given by the ratio of the new wavelength requirement and the

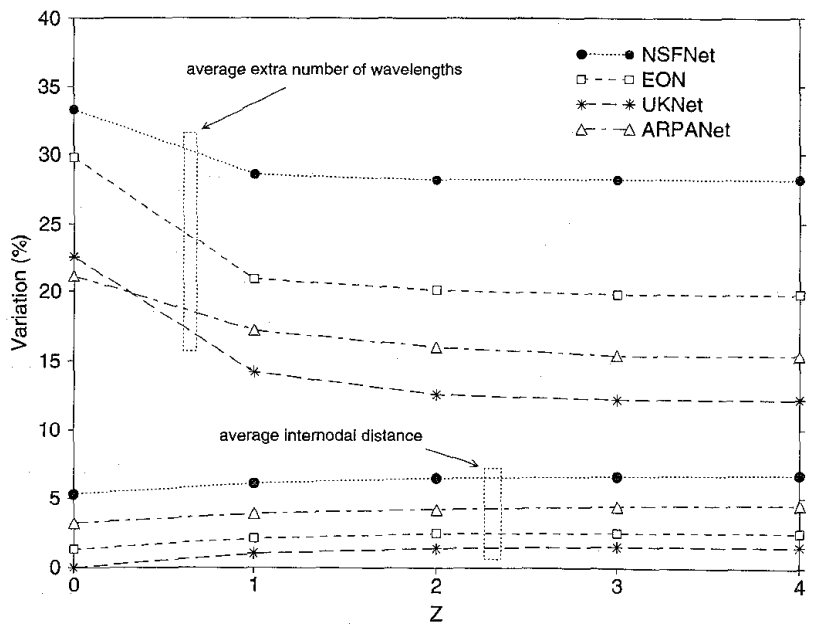

WD5 Fig. 2. Average percentage variation in the number of wavelengths and mean internodal distance vs. the number of additional hops $Z$.

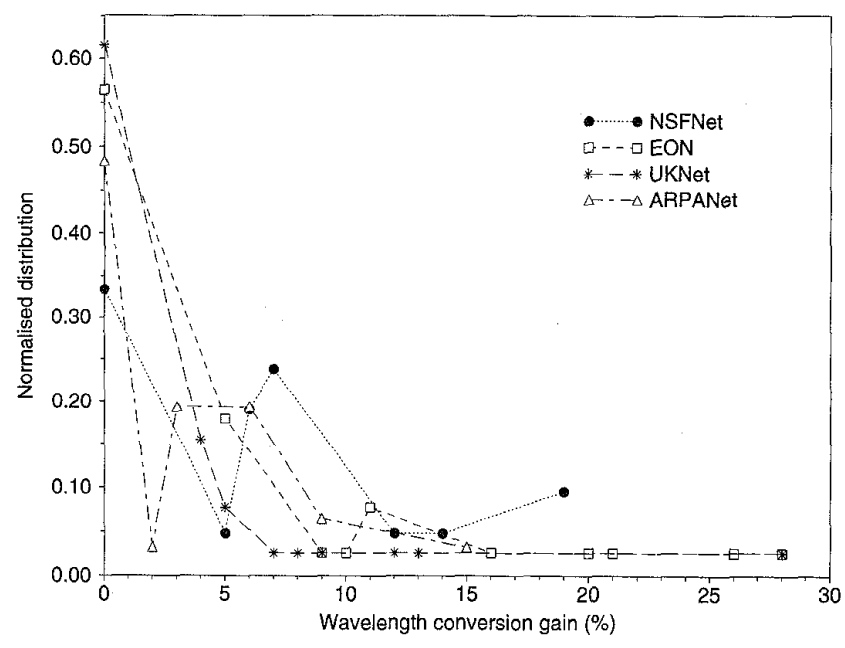

WD5 Fig. 3. Normalized distribution of the wavelength conversion gain (in \%).

number of channels in the new most loaded link(s). Figure 3 shows the results using only MNHs restoration paths. It should be noted that for all the analyzed topologies, in more than $80 \%$ of the link failures, wavelength conversion determines a reduction in the number of wavelengths of $10 \%$ or less. Similar results were obtained for many randomly generated network topologies. These results, in agreement with Ref. 4, quantify the benefit of wavelength conversion, and underline the importance of optimizing the restoration algorithm.

The influence of wavelength conversion in the case of nonuniform traffic is also presented. This can be particularly important for optimizing the transport network design.

1. See special issues on optical networks: M. Fujiwara et al., IEEE J. Lightwave Technol. 14, (1996), and R.L. Cruz et al., IEEE J. Select. Area Commun. 14, (1996).

2. S. Baroni, P. Bayvel, J.E. Midwinter, in Optical Fiber Communication Conference, Vol. 2 of 1996 OSA Technical Digest Series (Optical Society of America, Washington, D.C., 1996), pp. 25-26.

3. S. Baroni and P. Bayvel, Key topological parameters for the wavelength-routed optical networks design, to be presented at ECOC'96, Oslo, Norway, September 15-19, 1996.

4. R.A. Barry and P.A. Humblet, in Proceedings of IEEE INFOCOM'95, pp. $402-412$.

Impact on traffic and transmission performance of all-optical wavelength converters placed at the network interface or in OXCNs

B. Mikkelsen, H.N. Poulsen, S.L. Danielsen, C. Joergensen, M. Vaa, A. Klock, P.B. Hansen, K.E. Stubkjaer, K. Wünstel,* K. Daub,* E. Lach,* G. Laube,* W. Idler,* M. Schilling,* Center for Broadband Telecommunications, Department of Electromagnetics Systems Technical University of Denmark, Build. 348, DK-2800 Lyngby, Denmark

Wavelength-division multiplexing (WDM) networks will need optical wavelength converters (OWCs) in the optical cross-connecting nodes (OXCNs) or in transponders at the network interface to match the 

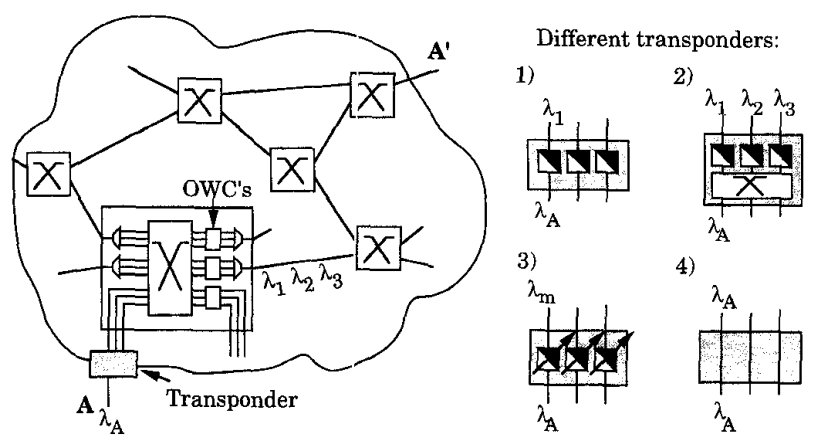

WD6 Fig. 1. Schematic of WDM network and different transponder configurations: the wavelength of user $A, \lambda_{A}$, is matched to a network wavelength $\left(\lambda_{1}, \lambda_{2}\right.$, $\left.\lambda_{3} \ldots \lambda_{m}\right)$. OWC: optical wavelength converter.

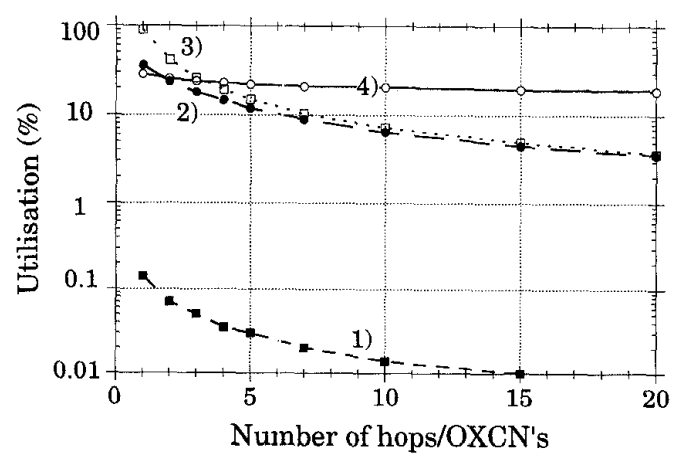

WD6 Fig. 2. Possible channel utilization as a function of number of hops/ $O X C s$ between user $A$ and $A^{\prime}$. The different transponder configurations given in Fig. 1 are the parameter; $(1-0)$ : fixed output wavelength, $(2-0)$ : OWCs + space switch, $(3-\square)$ : tunable OWC's, $(4-O)$ : OWCs in OXCNs.


WD6 Fig. 3. A) Measured penalty vs. interference cross talk with and without an interferometric wavelength converter (IWC) in the transmission path. B) Measured penalty vs. input power to EDFA with and without an interferometric wavelength converter (IWC) in the transmission path. Bit rate is $20 \mathrm{Gbit} / \mathrm{s}$ in both experiments.

incoming wavelengths to those of the network and to reduce blocking probability. ${ }^{1,2}$ In this paper we first perform a traffic analysis for different transponder configurations with and without converters in the OXCNs. Second, by experiments at $20 \mathrm{Gbit} / \mathrm{s}$ we demonstrate that all-optical interferometric wavelength converters ${ }^{3-5}$ placed in the OXCNs can reduce requirements to cross talk and amplified spontaneous emission due to a regenerative capability.

As shown in Fig. 1 we analyze three different transponder configurations for the case without OWCs in the OXCNs: (1) the user wavelength, $\lambda_{\mathrm{A}}$, is convertecl to a fixed network wavelength, or $\lambda_{\mathrm{A}}$ can be converted to any of the nitwork wavelengths by (2) placing a space switch in front of a converter array or (3) by tuneable converters. Finally, we analyze the situation (4) where the OXCNs deploy converters for which case no conversion is needed in the transponders.

For a fixed blocking probability of $10^{-3}$ in each of the four cases, Fig. 2 gives the possible channel utilization as a function of the number of $O X C N s$ between two users $\left(A\right.$ and $A^{\prime}$ ). The calculations are shown for a network constructed by OXCNs with four inlets and eight wavelengths per inlet. The results of Fig. 2 suggest that the converters should be placed in the OXCNs, particularly for large networks, and that case 1 gives unacceptable performance for all network sizes. This tendency is the same for other OXC sizes. The higher utilization in case 3 compared to 2 is because two users of the same transponder can utilize the same wavelengths to access two different outlets when using tunable converters. The higher utilization for cases 2 and 3 compared to 4 for a small number of hops is due to the favorization of the local data compared to remote data (this could also be arranged by a management system for case 4).

Placing interferometric wavelength converters (IWCs) in the OXCNs not only decreases the blocking probability but also improves the transmission performance of the optical network, because a regenerative capability in terms of noise and extinction ratio improvement is possible. ${ }^{3}$ This is demonstrated by a $20 \mathrm{Gbit} / \mathrm{s}$ experiment, where the penalty from interference cross talk is recorded with and without an $\mathrm{IWC}^{5}$ in the transmission path. The results shown in Fig. $3 \mathrm{~A}$ ) clearly demonstrate that the cross talk requirements can be relaxed by $4-5 \mathrm{~dB}$ by deploying IWCs. The sensitivity for the $20 \mathrm{Gbit} / \mathrm{s}$ input signal ( $1558 \mathrm{~nm})$ and converted signal $(1562 \mathrm{~nm})$ without cross talk is -24.8 and $-25 \mathrm{dBm}$, respectively.

Also shown in Fig. 3 is the measured penalty as function of the input power to an erbium-doped fiber amplifier (EDFA) with and without an IWC following the amplifier (bit rate is $20 \mathrm{Gbit} / \mathrm{s}$ ). Because of a nonlinear transfer function, the IWC improves the EDFA input dynamic range by 4 dB. Consequently, optical networks deploying IWCs in OXCNs are expected to allow more EDFAs to be cascaded.

In summary, placing OWCs in the OXCNs rather than at the network interface not only improves the traffic performance but also enhances the performance of the physical layer, e.g., in terms of relaxed cross talk requirements.

${ }^{*}$ Alcatel Telecom Research Division, Stuttgart, Germany

1. R.A. Barry and P. Humblet, IEEE J. Sel. Area Commun. 14, 858867 (1996).

2. M. Kovacevi'c and A. Acampora, IEEE J. Sel. Area Commun. 14, $868-880$ (1996).

3. B. Mikkelsen et al., Electron. Lett. 32, 566-567 (1996).

4. B. Mikkelsen et al, in Optical Fiber Communication Conference, Vol. 2 of 1996 OSA Technical Digest Series (Optical Society of America, Washington, D.C., 1996), paper PD13.

5. M. Schilling et al., in Optical Fiber Communication Conference, Vol. 2 of 1996 OSA Technical Digest Series (Optical Society of America, Washington, D.C., 1996), paper WG2. 